\title{
Current management of brain metastases
}

\author{
Pedro Tadao Hamamoto Filho', Vitor César Machado', Flávio Ramalho Romero², \\ Luis Gustavo Ducati', Marco Antônio Zanini³, Roberto Colichio Gabarra ${ }^{3}$
}

Faculdade de Medicina de Botucatu, Universidade Estadual Paulista “Júlio de Mesquita Filho” (Unesp), Botucatu, SP, Brasil.

\section{ABSTRACT}

Brain metastases are the most common tumors within the central nervous system. Recent advances on diagnosis and treatment modalities have allowed for longer survival. In this paper we review the indication of each modality of treatment: surgery, whole brain radiotherapy and stereotactic radiosurgery, as also recent advances on the knowledge of brain metastases biology that may improve the use of medical treatment and chemotherapy.

\section{KEYWORDS}

Neoplasm metastasis, brain neoplasms, neurosurgery, medical oncology, radiotherapy, radiosurgery.

\section{RESUMO}

Manejo atual de metástases cerebrais

Metástases cerebrais são os tumores mais comuns do sistema nervoso central. Avanços recentes no diagnóstico e modalidades de tratamento têm aumentado a sobrevida dos pacientes. Neste artigo, revisamos a indicação de cada modalidade de tratamento: cirurgia, radioterapia convencional, radiocirurgia estereotáxica, como também os recentes avanços no conhecimento da biologia das metástases cerebrais que poderão ampliar o uso do tratamento clínico com quimioterapia.

\section{PALAVRAS-CHAVE}

Metástase neoplásica, neoplasias encefálicas, neurocirurgia, oncologia, radioterapia, radiocirurgia.

1 Médico-residente em Neurocirurgia, Faculdade de Medicina de Botucatu (Unesp), Botucatu, SP, Brasil.

2 Neurocirurgião, Hospital das Clínicas da Unesp, Botucatu, SP, Brasil.

3 Professor-assistente doutor, Departamento de Neurologia, Psicologia e Psiquiatria da Unesp, Botucatu, SP, Brasil. 


\section{Introduction}

Brain metastases are the most common tumors within the central nervous system. ${ }^{1}$ It is estimated that about $8-10 \%$ of all adults with cancer will develop a symptomatic brain metastasis throughout the course of the disease. ${ }^{2}$

Main primary sites include lung, breast, kidney and melanoma. ${ }^{3}$ Proportions of primary sites of brain metastases are estimated to be $45 \%$ for lung carcinoma, $20 \%$ for breast carcinoma, $15 \%$ for melanoma, $10 \%$ for renal cell carcinoma, $5 \%$ for colon carcinoma and $5 \%$ for other tumors. However the propensity of these tumors to metastasize is different: $50 \%$ for melanoma, $25 \%$ for lung carcinoma, 25\% for breast carcinoma, $15 \%$ for renal cell carcinoma and $5 \%$ for colon carcinoma. ${ }^{4}$

Though recent advances in diagnosis and treatment techniques, overall median survival of patients with newly diagnosed brain metastases remains quite low. It varies from 4.9 months for small cell lung cancer to 13.8 months for breast cancer. ${ }^{5}$

Therapeutic options include surgery, whole brain radiotherapy (WBRT) and stereotactic radiosurgery (SRS). Chemotherapy has a limited role in the management of brain metastases but recent advances in the knowledge of their molecular biology may point future paradigm changes. ${ }^{6}$ In this paper we review current concepts in each modality of treatment.

\section{Surgery}

Surgery plays a key role in the management of brain metastases. It has many benefits: treatment of large lesions, rapid resolution of mass effect and edema, removal of the cancer, histologic confirmation of the cancer, rapid tapering of the dose of corticosteroids used to treat symptomatic lesions and requires less intensive follow-up than other modalities of treatment. ${ }^{7}$

Best indications for surgery are patients with good performance status and with stable extracranial cancer. ${ }^{8}$ When considering patient selection for surgical removal of brain metastases, one should analyze an expected survival higher than three months, a general medical condition that may withstand surgery and anesthesia, and a good neurological status (it is a Karnofsy Performance Status score of at least 70). Also the lesions should be resectable, that is accessible (not within brainstem, basal ganglia and thalamus), not numerous (maximum of three or four lesions) and not very small (at least 1 cm of diameter). ${ }^{4}$

It is important to note that gross total resection allows a significant longer survival.
Another concern in considering surgical management is to improve quality of life. This way, even patients with poor clinical conditions with short expected survival may be benefited with surgery for alleviating neurological symptoms. ${ }^{8}$ Hemiparesis and symptoms of intracranial hypertension are the most amenable to be improved after surgery, whereas aphasia and visual field defects may be even worsened after surgery. ${ }^{9}$

Finally median survival after surgery is 5.6-8.5 months. ${ }^{10,11}$ Still local postoperative recurrence is 46 $58 \%$ and combined conventional radiotherapy may reduce this risk. ${ }^{11}$

\section{Whole brain radiotherapy}

Radiotherapy is employed as adjuvant therapy after surgery in order to reduce local postoperative recurrence. It is the standard treatment for patients with multiple lesions. However recent improvements in systemic cancer control have prolonged overall survival and the benefits of WBRT have somehow been overweighed by its complications. Furthermore new studies have failed to show decreases in mortality. So its routine use as adjuvant therapy has been controversial. ${ }^{4}$

To note is the radiosensitivity of different brain metastases to conventional fractionated radiotherapy. Lymphoma, germinoma and small cell lung cancer are highly sensitive. Breast cancer, non-small lung cancer and colon cancer are intermediately sensitive. And melanoma, renal cancer and sarcoma are poorly sensitive., ${ }^{4,13}$

WBRT solely, as the once therapy for brain metastases, is preferred to patients with more than 4 lesions and patients with poor clinical conditions and short expected survival. ${ }^{14}$

WBRT have some limitations, mainly its side effects (neurocognitive impairment) and lack of sustained efficacy. ${ }^{11}$ Many studies have shown changes in neuropsychological assessments and neurocognitive functions through different validated instruments. There are deleterious effects on verbal memory, executive functioning, processing speech and auditory/verbal learning tests. ${ }^{15}$

Nowadays the strategy for single brain metastasis is to omit adjuvant WBRT until recurrence appears. This is will avoid the deleterious neurocognitive side effects of radiation and maintain WBRT as a salvage therapy.

\section{Stereotactic radiosurgery}

SRS is one of the newest modality of treatment for different brain disease. It has been largely used for 
brain metastases since it allows for the treatment of small and deep lesions, even within eloquent areas of the parenchyma. It is a minimally invasive approach that does not require general anesthesia, so that an outpatient fashion is possible. Multiple lesions can be treated during the same session. It has a short recovery time (generally lass than 1 week), allowing for a rapid initiation of systemic therapies. Finally, there is a potential avoidance of WBRT. ${ }^{7}$

Some characteristics make brain metastases ideal targets for SRS: well defined lesions on imaging examinations, spherical or pseudospherical shapes, less than $4 \mathrm{~cm}$ in maximum diameter, generally noninfiltrative, and located at gray-white junction. ${ }^{7}$

Good candidates for SRS are patients whose largest tumor has a volume smaller than $10 \mathrm{~cm}^{3}$, patients with a KPS equal or higher than 70 , without evidence of cerebrospinal fluid dissemination on imaging, with a total tumor volume of $15 \mathrm{~cm}^{3}$ and tumor number of 10 or less. ${ }^{16}$

Comparisons between surgery + WBRT versus SRS have controversial results. There are only 3 retrospective and 1 prospective study. It seems that there is no difference in survival, neurological death rates and freedom from local recurrence. ${ }^{11}$

\section{Chemotherapy and new target therapies}

Conventional chemotherapy has limited role in the management of brain metastases, as chemotherapy agents have poor penetrability to the central nervous system through the blood-brain barrier (BBB). ${ }^{6}$

New researches have improved the understanding on how metastatic cells cross the BBB, invade the parenchyma and interact with the brain microenvironment. Various mechanisms are involved in chemo-adhesion, tumor cell migration and adhesion to endothelial cell basement membrane, extracellular matrix degradation and angiogenesis. ${ }^{17}$

Genetic studies also present patterns of mutations for different metastases. Breast cancer has mutations on COX2, HBEGF, ST6GALNAC5, HK2, FOXC1, HER2 and VEGFA genes. Lung cancer shows mutation on VEGFA, LEF1, HOXB9, CDH2, KIFC1 and FALZ3 genes. Melanoma, on VEGFA and STAT3 genes. ${ }^{18}$

Together, these molecules and genes make particular cancers target for different immunological drugs. For breast cancer, tests involve Trastuzumab, Lapatinib, Interferon anfa-2a, Iniparib, Sunitinib, Vorinostat, Panobinostat and Bevacizumab. For non-small cell lung cancer, Erlotinib, Gefitinib, Vorinostat, Panobinostat and Bevacizumab. For melanoma, Vemurafenib, Ipilimumab, Interferon alfa-2a, Vorinostat, Panobinostat and Bevacizumab. Most of the clinical trials testing these agents are in phase II. ${ }^{6}$

Thus future work can identify therapeutic agents in order to prevent brain metastases from taking hold and treat established brain metastases. ${ }^{17}$

\section{How can we proceed?}

Clinical decision on treating patients with brain metastases must be individualized. One has to consider clinical experience, available facilities, scientific evidence, prognostic concerns, quality of life and patients' and families' wishes.

But some general guidelines may be useful.

First of all, consider the patient's functional status. A KPS lower than 70 points for WBRT or symptomatic treatment alone. Secondly, the control of systemic disease. Active extracranial disease with more than 3 or 4 lesions makes the patient candidate for WBRRT. Active extracranial disease with up to 3 lesions makes the patient candidate for WBRT with or without SRS. Patients with controlled systemic disease with more than 3 or 4 lesions should receive WBRT. Patients with controlled systemic disease with up to 3 lesions may be benefited with surgery and WBRT or SRS and WBRT. ${ }^{19}$

In another fashion, consider a patient with stable systemic disease. Then analyze the number of brain metastases and the KPS score. A patient with more than 4 lesions and a KPS $<80$ may be operated on for symptomatic control, since his lesions are resectable, and managed with partial or WBRT. Then, if there is a poor response, or tumor progression, or distant tumor recurrence, the patient may be candidate for SRS. On the other hand a patient with less than 4 lesions or with a KPS equal or higher than 80 may be managed with surgery or SRS. Close monitoring with serial imaging is needed. If there is distant or local recurrence, SRS may be repeated or a WBRT performed. Surgery remains amenable for symptomatic resectable metastases. ${ }^{14}$

\section{Case examples}

\section{Case 1}

A 63-years-old man was referred to our service with a complaint of headache and a right-sided he- 
miparesis for about one month. He had a positive history of smoking. MRI disclosed four metastatic lesions: one in the medial surface of the right central lobule (Figure 1A), one in the left occipital lobe (Figure $1 \mathrm{~B}$ ), one in the left frontal pole (Figure 1C) and one in the left middle frontal gyrus (Figure 1D). The last one was the larger and the responsible for the patient's symptoms. He was operated on to resect this lesion through a frontal craniotomy. It was diagnosed a brain metastasis from a previously unknown lung adenocarcinoma. Afterwards he received WBRT. At three-months follow-up a new MRI disclosed a reasonable local control (Figure $1 \mathrm{E}-\mathrm{H}$ ).

\section{Case 2}

A 34-years-old woman previously diagnosed with a ductal breast carcinoma searched for our department because of a progressive headache. Her neurological examination was unremarkable. A MRI showed a large metastasis within the left cerebellar hemisphere (Figure 2A) and a quite little metastasis in the left occipital lobe (Figure 2B). She was operated on through a suboccipital craniotomy to resect the cerebellar lesion. Then she was referred to SRS in order to treat the remaining lesion. A three-months follow-up MRI showed no residual lesion in the cerebellum (Figure 2C) and control of the tumor in the occipital lobe (Figure 2D).

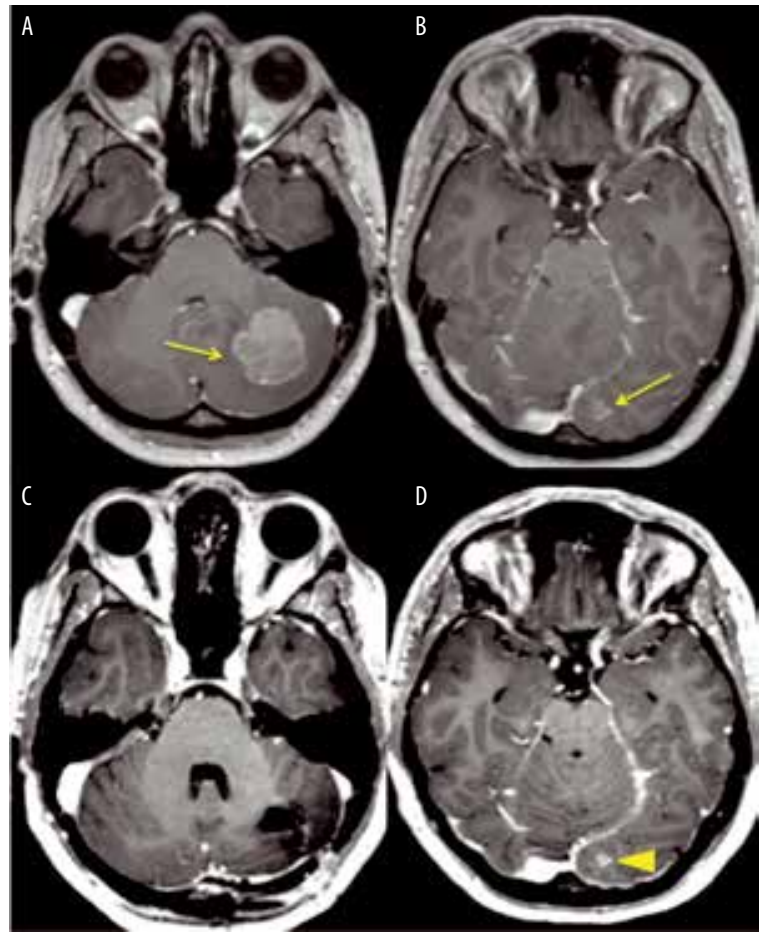

Figure 2 - MRI of a patient with breast cancer with two metastases to the brain (arrows): a large lesion in the left cerebellar hemisphere $(A)$ and a small lesion in the left occipital lobe (B). The large lesion was surgically resected and the little one was managed through SRS. Follow-up MRI showed local disease control $(C)$ and reduction in the size of the remaining lesion (arrow-head, D).

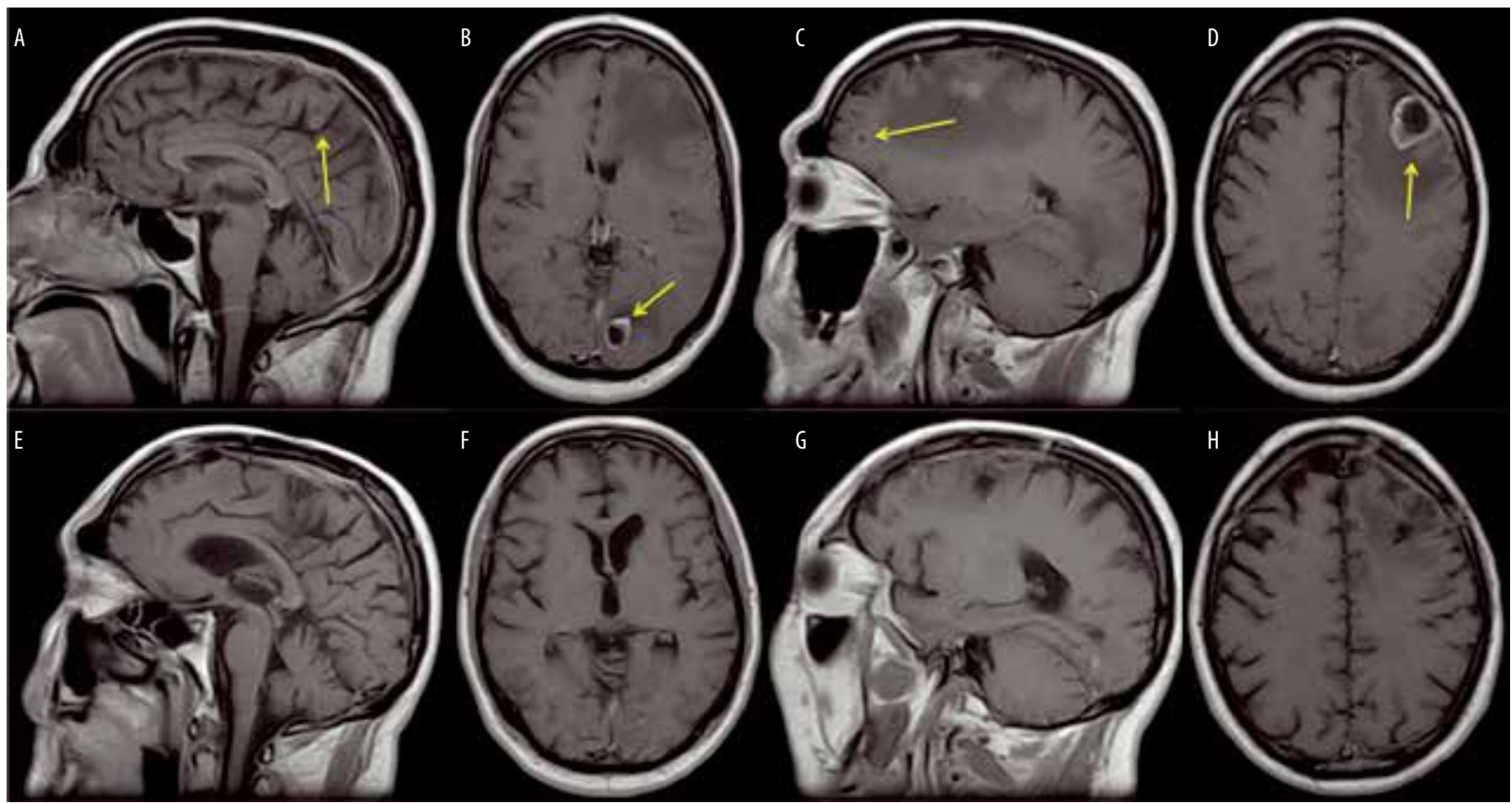

Figure 1 - MRI of a patient with multiple brain metastases (arrows), pre- (A-D) and post-treatment (E-H). The larger tumor in the left middle frontal gyrus was resected surgically. Afterwards, the patient had conventional radiotherapy. NB: images were not obtained through the same positioning protocol, so that we present the slices from the regions of interest. 


\section{Considerations}

Through several years treating brain metastases, neurosurgical community has faced significant advances. Nieder et al. ${ }^{20}$ compared two groups of treated patients, regardless of treatment modality: the first group was named contemporary and included patients treated from 2005 to 2009; the second group was named historical and included patients treated from 1983 to 1989. The rate of alive patients after 48 months of treatment increased significantly from the past to current days. ${ }^{20}$ That means it is worthy to keep studying the issue and employing new knowledge to clinical practice.

In Brazil few centers have SRS available in a large scale for treating patients with brain metastases, especially in the public health system. Government has to be called on to the need for technological improves.

Finally the words from Nieder et al. ${ }^{20}$ have to be kept in mind: "Avoiding overtreatment in patients with poor prognosis is as important as aggressive treatment in patients who might survive for several years."

\section{Conclusions}

Brains metastases are very common and every neurosurgeon will face them sometime. So it is important to know the very best treatment modality available for each patient and each disease.

\section{References}

1. Alexandru D, Bota DA, Linskey ME. Epidemiology of central nervous system metastases. Prog Neurol Surg. 2012;25:13-29.

2. Soffietti R, Rudà R, Trevisan E. Brain metastases: current management and new developments. Curr Opin Oncol. 2008;20(6):676-84.

3. Schouten LJ, Rutten J, Huveneers HA, Twijnstra A. Incidence of brain metastases in a cohort of patients with carcinoma of the breast, colon, kidney, and lung and melanoma. Cancer. 2002;94(10):2698-705.

4. Siu T, Lang FF. Surgical management of cerebral metastases. In: Quiñones-Hinojosa A, editor. Schmidek and Sweet. Operative neurosurgical techniques: indications, methods, and results. 6th ed. Philadelphia: Elsevier Saunders; 2012. p. 178-91.

5. Tsao MN, Rades D, Wirth A, Lo SS, Danielson BL, Gaspar LE, et al. Radiotherapeutic and surgical management for newly diagnosed brain metastasis(es). An American Society for Radiation Oncology evidence-based guideline. Pract Radiat Oncol. 2012;2(3):210-25.

6. Fokas E, Steinbach JP, Rödel C. Biology of brain metastases and novel targeted therapies: time to translate the research. Biochim Biophys Acta. 2013;1835(1):61-75.

7. Suh $\mathrm{JH}$. Stereotactic radiosurgery for the management of brain metastases. N Engl J Med. 2010;362(12):1119-27.

8. Lee CH, Kim DG, Kim JW, Han JH, Kim YH, Park CK, et al. The role of surgical resection in the management of brain metastasis: a 17-year longitudinal study. Acta Neurochir (Wien). 2013;155(3):389-97.

9. Schödel P, Schebesch KM, Brawanski A, Proescholdt MA. Surgical resection of brain metastases-impact on neurological outcome. Int J Mol Sci. 2013;14(5):8708-18.

10. Paek SH, Audu PB, Sperling MR, Cho J, Andrews DW. Reevaluation of surgery for the treatment of brain metastases: review of 208 patients with single or multiple brain metastases treated at one institution with modern neurosurgical techniques. Neurosurgery. 2005;56(5):1021-34.

11. Lippitz B, Lindquist C, Paddick I, Peterson D, O'Neill K, Beaney R. Stereotactic radiosurgery in the treatment of brain metastases: the current evidence. Cancer Treat Rev. 2014;40(1):48-59.

12. Cairncross JG, Kim JH, Posner JB. Radiation therapy for brain metastases. Ann Neurol. 1980;7(6):529-41.

13. Lang FF, Sawaya R. Surgical management of cerebral metastases. Neurosurg Clin N Am. 1996;7(3):459-84.

14. Khalsa SS, Chinn M, Krucoff M, Sherman JH. The role of stereotactic radiosurgery for multiple brain metastases in stable systemic disease: a review of the literature. Acta Neurochir (Wien). 2013;155(7):1321-7.

15. McDuff SG, Taich ZJ, Lawson JD, Sanghvi P, Wong ET, Barker FG 2nd, et al. Neurocognitive assessment following whole brain radiation therapy and radiosurgery for patients with cerebral metastases. J Neurol Neurosurg Psychiatry. 2013;84(12):1384-91.

16. Serizawa T, Higuchi $Y$, Nagano O. Stereotactic radiosurgery for brain metastases. Neurosurg Clin N Am. 2013;24(4):597-603.

17. Martinez N, Boire A, Deangelis LM. Molecular interactions in the development of brain metastases. Int $\mathrm{J}$ Mol Sci. 2013;14(8):17157-67.

18. Eichler AF, Chung E, Kodack DP, Loeffler JS, Fukumura D, Jain RK. The biology of brain metastases-translation to new therapies. Nat Rev Clin Oncol. 2011;8(6):344-56.

19. Gil-Gil MJ, Martinez-Garcia M, Sierra A, Conesa G, Del Barco S, González-Jimenez S, et al. Breast cancer brain metastases: a review of the literature and a current multidisciplinary management guideline. Clin TransI Oncol. 2014;16(5):436-46.

20. Nieder C, Spanne O, Mehta MP, Grosu AL, Geinitz H. Presentation, patterns of care, and survival in patients with brain metastases: what has changed in the last 20 years? Cancer. 2011;117(11):2505-12.

Correspondence address

Pedro Tadao Hamamoto Filho

Faculdade de Medicina de Botucatu

Departamento de Neurologia, Psicologia e Psiquiatria

Distrito de Rubião Jr, s/n

18618-970 - Botucatu, SP, Brazil

E-mail: pthamamotof@hotmail.com 